\title{
Value of intraoperative frozen section analysis in re- excision margin evaluation in breast-conserving surgery for cancer: a single institution experience
}

Jian Guo Shen

Sir Run Run Shaw hospital

Lin Bo Wang

Zhejiang University School of Medicine Sir Run Run Shaw Hospital

Zi Nong Jiang

Zhejiang University School of Medicine Sir Run Run Shaw Hospital

Xiao Ming Yuan

Zhejiang University School of Medicine Sir Run Run Shaw Hospital

Wen He Zhao

Zhejiang University School of Medicine Sir Run Run Shaw Hospital

Jun Shen ( $\nabla$ shenjun0909@zju.edu.cn )

Research

Keywords: frozen section, re-excised margin, breast cancer, partial mastectomy

Posted Date: April 9th, 2020

DOI: https://doi.org/10.21203/rs.3.rs-21408/v1

License: (c) (i) This work is licensed under a Creative Commons Attribution 4.0 International License.

Read Full License 


\section{Abstract}

Background. Previous studies have demonstrated that in women with breast cancer treated with breastconserving surgery (BCS), intraoperative frozen section analysis of lumpectomy margins results in a decrease in reoperation rates for margin control. However, the value of intraoperative frozen margin evaluation (FME) in re-excision margin analysis is not fully understood. We analyzed our breast cancer database to identify the value of intraoperative frozen section examination of specimens additionally resected prior to BCS.

Methods. We conducted a retrospective review of patients who underwent attempted BCS for breast cancer with routine intraoperative FME at our institution between January 1998 and May 2016. The number of FMEs was analyzed. We additionally analyzed factors associated with positive re-excised margins to identify correlations with patient characteristics.

Results. Of the 760 patients who underwent attempted BCS with routinely conducted intraoperative FME, frozen sections were obtained from the initial margin only in $82.5 \%(n=627)$, the initial margin as well as a one-time re-excision analysis in $15.8 \%(n=120)$, or the initial margin and two or more re-excision analyses in $1.7 \%$ (n-13). Based on the results of FME, 727 (95.6\%) of the patients underwent BCS, while the remaining 33 (4.4\%) converted to mastectomy. Among the patients who underwent BCS, $112(15.4 \%)$ had an initial positive margin on a FME, underwent one-time margin re-excision and achieved a marginfree status, while $1.6 \%$ underwent a second margin resection due to a positive result on the first re-excised margin. In total, $72.7 \%$ of the conversions to mastectomy were due to a positive initial margin. Univariate and multivariate analyses showed that patients with the ductal carcinoma in situ (DCIS) histological type were more likely to have repeatedly positive re-excised margins during BCS.

Conclusion. While routine intraoperative FME of re-excised margins provided only limited value in patients who underwent attempted BCS, this method may be beneficial in the subgroup of patients with the DCIS histological type.

\section{Background}

Breast-conserving surgery (BCS) with radiation therapy is now a "standard of care" for stage I/II breast cancer patients. The goal of BCS is optimal oncologic control and good cosmetic outcomes [1, 2]. The success of BCS is based on the ability to achieve adequate margins, since the surgical margin status is one of the strongest predictors of local recurrence [3-5]. It has been reported that $20-40 \%$ of BCS patients have positive margins after the surgery and will require a second surgery for re-excision [6-7]. Therefore, numerous approaches have been suggested to improve BCS by reducing the rate of margin positivity, to avoid reoperation [8].

Many methods of intraoperative evaluation have been employed to reduce the need for re-excision in patients undergoing BCS [9]; among these, intraoperative frozen section analysis is thought to be one of the most useful. In a recent systematic review of 37 studies that encompassed more than 3600 tumors 
analyzed using intraoperative frozen sections, the authors reported that re-excision rates decreased from $26 \%$ in patients who did not undergo this technique to $4 \%$ in patients who did [10]. However, few studies have specifically explored the value of intraoperative frozen section analysis in re-excised margin evaluation.

In our institution, intraoperative frozen margin evaluation (FME) of both the initial resection margin and any additional re-excised specimens has been implemented as a routine procedure in BCS since 1998. In the present study, we retrospectively analyzed the records of patients who underwent attempted BCS including intraoperative FME of suture-oriented margins, to evaluate the impact of this procedure on outcomes, especially in cases requiring re-excision margin evaluation.

\section{Patients And Methods}

\section{Patients}

After obtaining Institutional Review Board approval, we conducted a retrospective review of the breast cancer database of the Department of Surgical Oncology at Sir Run Run Shaw Hospital, Hangzhou, China, to identify breast cancer patients who underwent BCS between January 1998 and May 2016. Informed consent was obtained from all patients prior to surgery. BCS candidates were identified based on clinical and radiographic evaluations performed prior to surgery, and routinely underwent preoperative breast magnetic resonance imaging. All patients who were converted to mastectomy due to positive margins on a FME sample after the first BCS attempt were included.

Patient demographic characteristics; menopausal status; operative records; pathologic tumor size; tumor type, localization, grade, estrogen/progesterone receptor status, C-erbB2 status, axillary pathologic nodal status, and stage; and frozen section results were recorded.

During BCS, the surgical margins of frozen tissue sections were routinely evaluated intraoperatively. In each case, the margin was oriented by suture marking, during which the surgeon usually placed four sutures to orient the specimen in four directions. The pathological features of the resected specimens were evaluated by pathologists according to the General Rules for Clinical and Pathological Recording of Breast Cancer. In general, margin shaving was not performed when an intraoperative FME revealed a margin-free status. However, if the margin was found on pathology to be positive or suspicious, the surgeons decided whether further excision or conversion to mastectomy should be performed. Margin reexcision was performed by harvesting a rectangular-shaped cavity margin by shaving along the circumference of the lumpectomy cavity at the sites where the margin was positive. A suture was intraoperatively placed on the side of the specimen opposite the margin cavity. All specimens were sent to Pathology with comments so that the sutures could be matched to specified margins. Generally, when the surgeons needed to perform a further 2-3 resections and the margins remained positive or the preservation of aesthetics no longer seemed possible, treatment was converted to mastectomy. 
After surgery, the patients received adjuvant radiation and systemic therapy according to the guidelines of the National Cancer Comprehensive Network and the Chinese Anti-Cancer Association. The patients were followed up regularly every 3 months for the first 2 years after surgery and then every 6 months for 2 years.

\section{Statistical analysis}

Statistical analyses were performed using SPSS 22.0. The chi-squared test or Fisher's exact test was used to evaluate associations between clinicopathological factors and the rate of positive re-excised margins. An independent two-sample t test was used for continuous, normally distributed variables. Multivariate analysis was performed using a logistic regression model. A P value of $<0.05$ was considered statistically significant.

\section{Results}

Seven hundred and sixty patients who underwent attempted BCS at our institution were enrolled in this study. Intraoperative frozen section analysis of the initial surgical margins was routinely performed in all patients, and additional re-excised margins were conducted when necessary. Based on the results of FME, 727 (95.6\%) patients underwent BCS, and the remaining 33 (4.4\%) patients were converted to mastectomy. The patients' demographic and pathological characteristics are summarized in Table 1. 
Table 1

Clinical characteristics of 760 patients with attempted BCS

\section{Overall patients}

\begin{tabular}{|c|c|c|}
\hline & $\mathrm{N}$ & $\%$ \\
\hline Age (median, years) & 48.2 & $22-80$ \\
\hline \multicolumn{3}{|l|}{ Menopause } \\
\hline No & 468 & 61.8 \\
\hline Yes & 289 & 38.2 \\
\hline Tumor size (mean, cm) & 1.86 & $0.5-6.0$ \\
\hline \multicolumn{3}{|l|}{ Location } \\
\hline Left & 397 & 52.3 \\
\hline Right & 358 & 47.2 \\
\hline Bilateral & 4 & 0.5 \\
\hline \multicolumn{3}{|l|}{ Histology } \\
\hline DCIS & 35 & 4.6 \\
\hline IBC & 725 & 95.4 \\
\hline \multicolumn{3}{|l|}{ LN metastasis } \\
\hline Yes & 231 & 30.4 \\
\hline No & 529 & 69.6 \\
\hline \multicolumn{3}{|l|}{ Lymphovascular invasion } \\
\hline Yes & 16 & 2.1 \\
\hline No & 744 & 97.9 \\
\hline \multicolumn{3}{|l|}{ HR status } \\
\hline Negative & 175 & 23.2 \\
\hline Positive & 580 & 76.8 \\
\hline \multicolumn{3}{|l|}{ Her-2 status } \\
\hline Negative & 577 & 78.7 \\
\hline Positive & 119 & 16.2 \\
\hline Controversial & 37 & 5.1 \\
\hline
\end{tabular}




\section{Overall patients}

\section{NAC}

\begin{tabular}{lcc} 
Yes & 100 & 13.2 \\
No & 655 & 86.8 \\
\hline SLN biopsy & 325 & 44.1 \\
Yes & 412 & 55.9 \\
\hline No & & \\
\hline Surgical type & 727 & 95.6 \\
$\begin{array}{l}\text { BCS } \\
\text { Mastectomy }\end{array}$ & 33 & 4.4 \\
$\begin{array}{l}\text { DCIS: ductal carcinoma in situ; IBC: invasive breast carcinoma; HR: hormone receptor; NAC: } \\
\text { neoadjuvant chemotherapy }\end{array}$
\end{tabular}

The proportions of patients in whom frozen sections were collected only at the initial margin, at the initial margin plus in addition to on re-excision, and at the initial margin plus two or more re-excisions were $82.5 \%, 15.8 \%$ and $1.7 \%$, respectively. Among the 727 patients who ultimately underwent BCS, in 112 patients $(15.4 \%)$, the initial margin sample was positive, and the patient underwent a single margin reexcision that was margin-free (negative), while only $12(1.6 \%)$ had a positive initial margin sample and a positive first re-excision and therefore needed at least one additional margin re-excision. Among the 33 patients who were converted to mastectomy, $72.7 \%$ converted because the margin of the initial frozen sample was positive. There was no difference in the number of FMEs performed between the patients who underwent BCS and those who converted to mastectomy $(p=0.315)$ (Fig. 1).

Among the 727 patients who ultimately underwent BCS, intraoperative FME to a re-excision margin was more likely to be performed in patients with the ductal carcinoma in situ (DCIS) histological type than in those with invasive carcinomas. However, age, tumor size, lymphovascular invasion, $\mathrm{N}$ stage, estrogen receptor (ER) status, progesterone receptor (PR) status, human epidermal growth factor receptor 2 (HER2) status, and neoadjuvant chemotherapy were not associated with the number of FMEs (Table 2). 
Table 2

Correlation between the number of FME procedures performed and clinicopathological features in 727 patients who underwent BCS

\begin{tabular}{|c|c|c|c|c|c|c|c|}
\hline & \multicolumn{2}{|c|}{ Initial FME } & \multicolumn{2}{|c|}{$\begin{array}{l}\text { Initial plus re- } \\
\text { excision FME }\end{array}$} & \multicolumn{2}{|c|}{$\begin{array}{l}\text { Initial plus two or more re- } \\
\text { excision FME }\end{array}$} & \multirow[t]{2}{*}{$\begin{array}{l}P \\
\text { value }\end{array}$} \\
\hline & $\mathrm{N}$ & $\%$ & $\mathrm{~N}$ & $\%$ & $\mathrm{~N}$ & $\%$ & \\
\hline $\begin{array}{l}\text { Age (median, } \\
\text { years) }\end{array}$ & 50.1 & $\begin{array}{l}22- \\
80\end{array}$ & 49.9 & $23-80$ & 45.2 & $29-53$ & 0.318 \\
\hline $\begin{array}{l}\text { Tumor size (mean, } \\
\mathrm{cm} \text { ) }\end{array}$ & 1.82 & $\begin{array}{l}0.5- \\
6\end{array}$ & 1.93 & $0.5-6$ & 2.0 & $1-5$ & 0.449 \\
\hline Location & & & & & & & 0.067 \\
\hline Left & 313 & 52.0 & 62 & 55.4 & 5 & 41.7 & \\
\hline Right & 288 & 47.8 & 48 & 42.9 & 6 & 50.0 & \\
\hline Bilateral & 1 & 0.2 & 2 & 1.8 & 1 & 8.3 & \\
\hline Histology & & & & & & & 0.003 \\
\hline DCIS & 22 & 3.6 & 4 & 3.6 & 4 & 33.3 & \\
\hline IBC & 581 & 96.4 & 108 & 96.4 & 8 & 66.7 & \\
\hline LN metastasis & & & & & & & 0.762 \\
\hline Yes & 169 & 28.7 & 26 & 23.4 & 3 & 27.3 & \\
\hline No & 420 & 71.3 & 85 & 76.6 & 8 & 72.7 & \\
\hline $\begin{array}{l}\text { Lymphovascular } \\
\text { invasion }\end{array}$ & & & & & & & 0.898 \\
\hline Yes & 10 & 1.7 & 2 & 1.8 & 0 & 0 & \\
\hline No & 593 & 98.3 & 110 & 98.2 & 12 & 100 & \\
\hline HR status & & & & & & & 0.850 \\
\hline Negative & 142 & 23.7 & 26 & 23.2 & 2 & 16.7 & \\
\hline Positive & 458 & 76.3 & 86 & 76.8 & 10 & 83.3 & \\
\hline Her-2 status & & & & & & & 0.915 \\
\hline Negative & 457 & 78.7 & 85 & 76.6 & 10 & 83.3 & \\
\hline Positive & 93 & 16.0 & 20 & 18 & 2 & 16.7 & \\
\hline Controversial & 31 & 5.3 & 6 & 5.4 & 0 & 0 & \\
\hline
\end{tabular}




\begin{tabular}{|lcccccc|}
\hline & Initial FME & $\begin{array}{l}\text { Initial plus re } \\
\text { excision FME }\end{array}$ & $\begin{array}{l}\text { Initial plus two or more re } \\
\text { excision FME }\end{array}$ & $\begin{array}{l}\text { P } \\
\text { value }\end{array}$ \\
\hline NAC & 83 & 13.9 & 10 & 9.0 & 1 & 8.3 \\
\hline Yes & 516 & 86.1 & 101 & 91.0 & 11 & 91.7 \\
\hline No & & & & & \\
\hline $\begin{array}{l}\text { DCIS: ductal carcinoma in situ; IBC: invasive breast carcinoma; HR: hormone receptor; NAC: } \\
\text { neoadjuvant chemotherapy }\end{array}$ & & & \\
\hline
\end{tabular}

To identify factors associated with a positive re-excision margin, we compared patients in whom residual disease was found on the re-excised specimens with those who achieved margin-free status in re-excised specimens. The DCIS histological type was significantly associated with a positive re-excised margin. Multivariate analysis with a logistic regression model revealed that the DCIS histological type was an independent predictor of a positive re-excised margin. These results are summarized in Table 3. 
Table 3

Univariate and multivariate logistic regression analyses of clinicopathological factors in the prediction of positive re-excised margins

\begin{tabular}{|c|c|c|c|c|c|c|}
\hline & \multicolumn{3}{|c|}{ Univariate } & \multicolumn{3}{|c|}{ multivariate } \\
\hline & OR & $95 \% \mathrm{Cl}$ & $\begin{array}{l}P \\
\text { value }\end{array}$ & OR & $95 \% \mathrm{Cl}$ & $\begin{array}{l}\mathrm{P} \\
\text { value }\end{array}$ \\
\hline $\begin{array}{l}\text { Age (years) } \\
\text { (<50 vs. }>=50)\end{array}$ & 0.255 & $\begin{array}{l}0.055- \\
1.199\end{array}$ & 0.084 & 0.166 & $\begin{array}{l}0.026- \\
1.059\end{array}$ & 0.058 \\
\hline $\begin{array}{l}\text { Tumor size } \\
(<=2 \mathrm{~cm} \text { vs. }>2 \mathrm{~cm})\end{array}$ & 1.471 & $\begin{array}{l}0.449- \\
4.820\end{array}$ & 0.524 & 1.214 & $\begin{array}{l}0.287- \\
5.138\end{array}$ & 0.793 \\
\hline $\begin{array}{l}\text { Histology } \\
\text { ( DCIS vs. IBC) }\end{array}$ & 0.098 & $\begin{array}{l}0.022- \\
0.430\end{array}$ & 0.002 & 0.041 & $\begin{array}{l}0.004- \\
0.392\end{array}$ & 0.006 \\
\hline $\begin{array}{l}\text { LN metastasis } \\
\text { ( Yes vs. No) }\end{array}$ & 1.023 & $\begin{array}{l}0.259- \\
4.035\end{array}$ & 0.974 & 1.113 & $\begin{array}{l}.0198- \\
6.248\end{array}$ & 0.903 \\
\hline $\begin{array}{l}\text { Lymphovascular invasion (Yes vs. } \\
\text { No) }\end{array}$ & 2.417 & $\begin{array}{l}0.250- \\
23.403\end{array}$ & 0.446 & 9.687 & $\begin{array}{l}0.337- \\
27.546\end{array}$ & 0.185 \\
\hline $\begin{array}{l}\text { HR status } \\
\text { (Negative vs. Positive) }\end{array}$ & 1.674 & $\begin{array}{l}0.350- \\
8.005\end{array}$ & 0.477 & 0.866 & $\begin{array}{l}0.133- \\
5.639\end{array}$ & 0.880 \\
\hline $\begin{array}{l}\text { Her-2 status } \\
\text { (Negative vs. Positive) }\end{array}$ & 0.575 & $\begin{array}{l}0.145- \\
2.276\end{array}$ & 0.430 & 0.092 & $\begin{array}{l}0.006- \\
1.430\end{array}$ & 0.088 \\
\hline $\begin{array}{l}\text { NAC } \\
\text { (No vs. Yes) }\end{array}$ & 0.818 & $\begin{array}{l}0.097- \\
6.900\end{array}$ & 0.854 & 0.408 & $\begin{array}{l}0.023- \\
7.341\end{array}$ & 0.543 \\
\hline
\end{tabular}

\section{Discussion}

In the present study, we found that only a small proportion of patients $(1.6 \%)$ required additional reexcision after the initial sample and first re-excision were both positive, and whether the patient decided to convert to mastectomy was not dependent on the results of the re-excised margin. However, the positive re-excision margin rate was higher in patients with the DCIS histological type than in patients with invasive carcinomas. These results suggest that while the value of intraoperative frozen section analysis in re-excised margins may be limited in the general population of patients undergoing attempted BCS, this process may be useful in specific subgroups of patients, such as those with the DCIS histological type.

The success of BCS relies on the achievement of negative margins. Leaving tissue adjacent to a positive excised margin in situ significantly increases the risk of ipsilateral breast cancer recurrence in both invasive disease and DCIS. Consequently, during BCS, a sample with a positive margin should prompt 
surgical re-excision [11-13]. In 2014, the Society of Surgical Oncology and the American Society for Radiation Oncology established consensus guidelines on margins for BCS that stated there should be "no ink on the tumor", meaning that the margin should be completely clear, and although this change in standards did lead to a $16 \%$ reduction in additional surgeries after initial lumpectomy, $22 \%$ of patients treated with BCS have been found still to require additional surgery [14]. In the present study, 603 of 727 patients $(82.9 \%)$ underwent a single intraoperative FME that showed a margin-free status. Based on the current standards, our results indicate that the remaining patients (17.1\%) in whom the initial FME was not negative would have been at a higher risk of needing to undergo additional re-operation after the initial lumpectomy if intraoperative FME had not been available in our institution.

Trials have consistently shown that frozen section analysis decreases the rate of reoperations for margins, and the impact of intraoperative margin management options is greatest in populations in which the baseline rates of inadequate margins are high [15]. Furthermore, while studies have suggested that frozen section analysis should always be considered except in populations in which the reoperation rate is already low $(15 \%)$, the significance of the impact of this procedure has remained unclear in populations with baseline re-operation risk rates that fall below $20 \%$ [16]. In the present study, the baseline rate of inadequate margins was $17.1 \%$, and $15.4 \%$ of all patients underwent a single margin reexcision procedure that resulted in a margin-free status after the initial frozen margin was positive. These results indicate that $98.4 \%$ of the patients in this study may have avoided a re-operation due to a positive margin because the initial resection margin was evaluated by frozen section analysis, allowing them to undergo re-excision. These results are in accordance with a previous study reported by Chen et al., who found that $16 \%$ of patients with an initially positive margin underwent intraoperative re-excisions and ultimately achieved successful BCS; the surgical treatment, margin management strategy and frozen section analysis used in their study were quite similar to those used in ours [17]. Together, these findings indicate that using intraoperative frozen section analysis for initial resection margin evaluation revealed that some patients had positive margins, thus allowing re-excision, which could reduce the reoperation rate in populations in which the baseline rate of inadequate margins is lower than $20 \%$.

The value of intraoperative FME for identifying margins that should be re-excised has rarely been studied. Jorns et al reported that use of FME for reexcision specimens resulted in no difference in the need for further reexcision or ultimate conversion to mastectomy because of a similar high false negative rate of FME in re-excision specimens (13\%) as compared with that of lumpectomy series (10\%) [18]. Based on these findings, the authors suggested that FME may not provide added value for patients undergoing reoperation for margins. Even so, most hospitals in China choose intraoperative frozen section analysis for margin evaluation, and in our institution, intraoperative FME for re-excision of margins is routinely conducted ( a cavity-shaving procedure is not generally performed even though this procedure has been associated with a lower rate of positive margins in a prospective randomized trial and multiple cohort studies [19]). In the present study, we found that in $98.4 \%$ of attempted BCS patients (82.9\% with initially margin free and $15.4 \%$ with a single margin-free re-excision), the risk of reoperation was either verified to be low or actually lowered as a result of the initial frozen tissue resection margin evaluation. Because only twelve patients (1.6\%) in this study required an additional margin re-excision after the first re-excised 
margin was positive, we suggest that FME at re-excision margins could be omitted if cavity shaving, which is recommended for re-excised margins, is always performed after the initial margin evaluation. Secondly, the rate of positivity for re-excision margins was $9.6 \%$ in our study, which is similar to previously published false-negative rates reported for FME in re-excision specimens (ranging from 3.513\%)[20]. It is therefore possible that the re-operation rate may not be reduced by the intraoperative evaluation of frozen sections of re-excised margins. Our results also reveal that a large proportion of the patients $(72.7 \%)$ with a positive initial margin converted to mastectomy, and that only a small proportion of these patients $(3 \%)$ converted to another therapy based on this result. These results collectively demonstrate that FME for re-excision margins may not influence surgical decisions during BCS.

Several studies have constructed nomograms to predict the likelihood of having positive initial margins during BCS and have significantly associated the DCIS histological type with initial margin positivity [21.22]. However, the risk factors for re-excision margin positivity have rarely been reported. In the present study, there was a greater increase in the proportion of patients with the DCIS histological type in the reexcision margin-positive group than in the re-excision margin-negative group and in patients who converted to mastectomy than in those with successful partial mastectomy (data not shown). The multivariate analysis also showed that the DCIS histological type was an independent risk factor for reexcised margin involvement in patients undergoing BCS. These data demonstrate that the subgroup of patients with the DCIS histopathologic type is associated with a reduced ability to acceptable margin status, and intraoperative FME of re-excision specimens may therefore be valuable in this subgroup of patients.

In conclusion, although the present study represents a retrospective analysis, our results show that while routine intraoperative frozen section analysis of re-excised margins may have limited value in the general population undergoing BCS, this process could benefit patients with the DCIS histological type undergoing this procedure.

\section{Abbreviations}

BCS: breast conserving surgery; FME: frozen margin evaluation; DCIS: ductal carcinoma in situ; ER: estrogen receptor; PR: progesterone receptor; HER2: human epidermal growth factor receptor 2.

\section{Declarations}

\section{Ethics approval and consent to participate}

This study was approved by Sir Run Run Shaw hospital review board. Patient consent was obtained before surgery.

\section{Consent for publication}

Not applicable. 
Availability of data and materials

The datasets used and/or analyzed during the current study are available from the corresponding author on reasonable request

Competing interests

The authors declare that they have no competing interests.

\section{Funding}

Not applicable

\section{Authors' contributions}

JGS and JS were responsible for the conception, design, and acquisition of data, JS, ZNJ and LBW analyzed and interpreted the data. JGS wrote the final draft. All authors read and approved the final manuscript.

\section{Acknowledgements}

Not applicable

\section{References}

1. Fisher B, Anderson S, Bryant J, Margolese RG, Deutsch M, Fisher ER, et al. Twenty-year follow-up of a randomized trial comparing total mastectomy, lumpectomy, and lumpectomy plus irradiation for the treatment of invasive breast cancer. N Engl J Med. 2002;347:1233-41.

2. Veronesi U, Cascinelli N, Mariani L, Greco M, Saccozzi R, Luini A, et al. Twenty-year follow-up of a randomized study comparing breast-conserving surgery with radical mastectomy for early breast cancer. N Engl J Med. 2002;347:1227-32.

3. Smitt MC, Nowels KW, Zdeblick MJ, Jeffrey S, Carlson RW, Stockdale FE, et al. The importance of the lumpectomy surgical margin status in long-term results of breast conservation. Cancer. 1995;76(2):259-67.

4. Tartter PI, Kaplan J, Bleiweiss I, Gajdos C, Kong A, Ahmed S, et al. Lumpectomy margins, reexcision, and local recurrence of breast cancer. Am J Surg. 2000;179(2):81-5.

5. Schulman AM, Mirrielees JA, Leverson G, Landercasper J, Greenberg C, Wilke LG. Reexcision Surgery for Breast Cancer: An Analysis of the American Society of Breast Surgeons (ASBrS) MasterySM Database Following the SSO-ASTRO "No Ink on Tumor" Guidelines. Ann Surg Oncol. 2017;24(1):528.

6. Wilke LG, Czechura T, Wang C, Lapin B, Liederbach E, Winchester DP, et al. Repeat surgery after breast conservation for the treatment of stage 0 to II breast carcinoma: a report from the National Cancer 
Data Base, 2004-2010. JAMA Surg. 2014;149(12):1296-305.

7. van Leeuwen MT, Falster MO, Vajdic CM, Crowe PJ, Lujic S, Klaes E, Jorm L, et al. Reoperation after breast-conserving surgery for cancer in Australia: statewide cohort study of linked hospital data. BMJ Open. 2018;8(4):e020858.

8. Angarita FA, Nadler A, Zerhouni S, Escallon J. Perioperative measures to optimize margin clearance in breast conserving surgery. Surg Oncol. 2014;23(2):81-91.

9. Nayyar A, Gallagher KK, McGuire KP. Definition and Management of Positive Margins for Invasive Breast Cancer. Surg Clin North Am. 2018;98(4):761-71.

10. Gray RJ, Pockaj BA, Garvey E, Blair S. Intraoperative Margin Management in Breast-Conserving Surgery: A Systematic Review of the Literature. Ann Surg Oncol. 2018;25(1):18-27.

11. Gage I, Schnitt SJ, Nixon AJ, Silver B, Recht A, Troyan SL, et al. Pathologic margin involvement and the risk of recurrence in patients treated with breast-conserving therapy. Cancer. 1996;78:1921-8.

12. Houssami N, Macaskill P, Marinovich ML, Morrow M. The association of surgical margins and local recurrence in women with early-stage invasive breast cancer treated with breast-conserving therapy: a meta-analysis. Ann Surg Oncol. 2014;21:717-730.

13. Wapnir IL, Dignam JJ, Fisher B, Mamounas EP, Anderson SJ, Julian TB, et al. Long-term outcomes of invasive ipsilateral breast tumor recurrences after lumpectomy in NSABP B-17 and B-24 randomized clinical trials for DCIS. J NatlCancer Inst. 2011;103:478-488.

14. Morrow M, Abrahamse P, Hofer TP, Ward KC, Hamilton AS, Kurian AW, et al. Trends in reoperation after initial lumpectomy for breast cancer: addressing overtreatment in surgical management. JAMA Oncol. 2017;3:1352-7.

15. Osborn JB, Keeney GL, Jakub JW, Degnim AC, Boughey JC. Cost-effectiveness analysis of routine frozen-section analysis of breast margins compared with reoperation for positive margins. Ann Surg Oncol. 2011;18:3204-9.

16. Singh M, Singh G, Hogan KT, Atkins KA, Schroen AT. The effect of intraoperative specimen inking on lumpectomy re-excision rates. World J Surg Oncol. 2010;8:4.

17. Chen K, Zeng Y, Jia H, Jia W, Yang H, Rao N, et al. Clinical outcomes of breast-conserving surgery in patients using a modified method for cavity margin assessment. Ann Surg Oncol. 2012;19(11):3386-94.

18. Jorns JM, Daignault S, Sabel MS, Wu AJ. Is intraoperative frozen section analysis of re-excision specimens of value in preventing reoperation in breast-conserving therapy? Am J Clin Pathol. 2014;142:601-8.

19. Chagpar AB, Killelea BK, Tsangaris TN, Butler M, Stavris K, Li F, et al. A Randomized, Controlled Trial of Cavity Shave Margins in Breast Cancer. N Engl J Med. 2015;373(6):503-10.

20. Jorns JM, Visscher D, Sabel M, Breslin T, Healy P, Daignaut S, et al. Intraoperative frozen section analysis of margins in breast conserving surgery significantly decreases reoperative rates: one-year experience at an ambulatory surgical center. Am J Clin Pathol. 2012;138:657-69. 
21. Lai HW, Huang RH, Wu YT, Chen CJ, Chen ST, Lin YJ, et al. Clinicopathologic factors related to surgical margin involvement, reoperation, and residual cancer in primary operable breast cancer - An analysis of 2050 patients. Eur J Surg Oncol. 2018;44(11):1725-35.

22. Pan Z, Zhu L, Li Q, Lai J, Peng J, Su F, et al. Predicting initial margin status in breast cancer patients during breast-conserving surgery. Onco Targets Ther. 2018;11:2627-35.

\section{Figures}

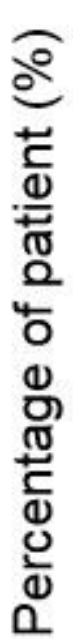

90
80
70
60
50
40
30
20
10
0

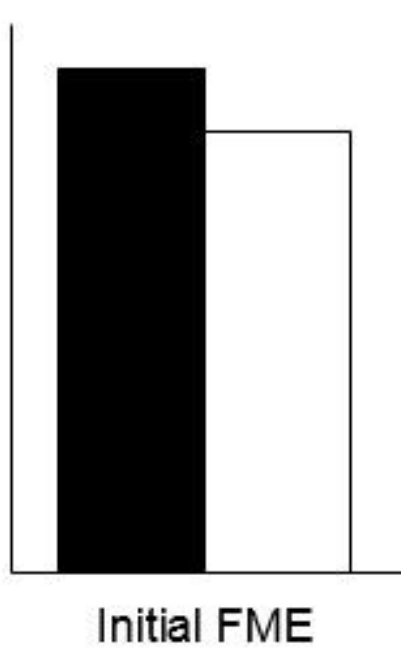

- BCS $\square$ Mastectomy

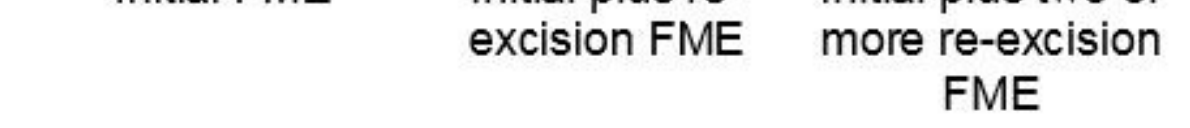

Number of Frozen Margin Excision Procedures

Figure 1

Correlation between the number of FMEs and surgical type in 760 patients who underwent attempted BCS 